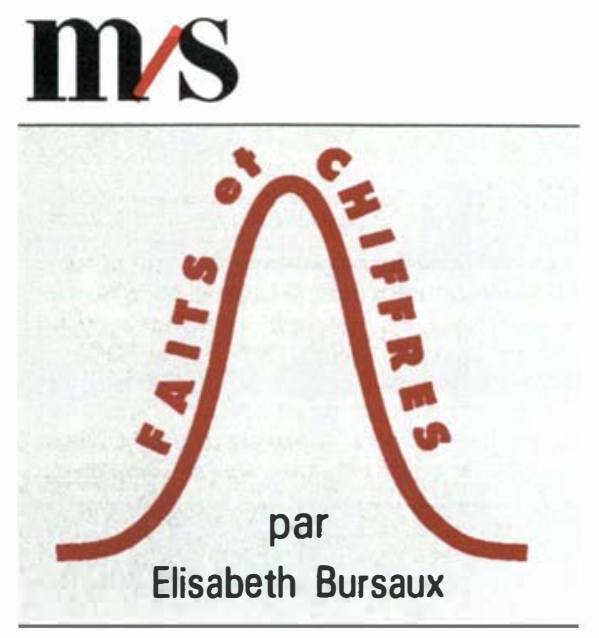

\title{
Population de la Russie : évaluation au 1er janvier 1992
}

Source: A. Avdeyev et A. Monnier. Population et Sociétés, INED (Institut national d'études démographiques), juin 1993, $\mathrm{n}^{\circ} 280$.

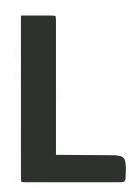

es effets démographiques de la Première Guerre Mondiale, de la Révolution et de la guerre civile commencent à s'estomper sur la pyramide des âges de la Russie (figure 1), mais les traces de la chute de la natalité (quasi-division par deux entre 1914 et 1917) subsistent encore, particulièrement chez les femmes (1). Chez les hommes, ce phénomène est moins pcrceptiblc en raison des pertes (2) qu'ont subies, durant la Seconde Guerre Mondiale, ces classes creuses. La guerre, conjuguée à l'alcoolisme, déséquilibre le sommet de la pyramide : en Russie, il y a 3,1 femmes pour un homme au-dessus de 70 ans (en France 1,7 ; en Allemagne 2,1).

Toutefois, dès 1918 la natalité connaît une reprise qui se poursuivra malgré la guerre civile (3). Vers 1927 , le nombre des naissances égale celui des années 1913-1914. La collectivisation de l'agriculture provoque une baisse de la natalité qui prendra les dimensions d'une crise avec la famine de 1932-1933 (4). La légère reprise qui fait suite, dès 1934 , sera provisoirement renforcée par l'interdiction de l'avortement en 1936 (5). L'effondrement de la natalité durant la Seconde Guerre Mondiale a été plus massif encore que pendant la première (6). En 1943, il y a eu environ trois fois moins de naissances que dans les années qui ont précédé la guerre. Après la fin du conflit il y a eu un baby-boom (7) comme dans les pays occidentaux. Mais il n'y a pas eu d'augmentation de fécondité pour compenser l'arrivée des classes creuses 1940-1945 aux âges de la fécondité. Dans ces conditions, la baisse de la natalité des années 1960 est la conséquence de celle de la guerre. La politique du début des années 1980 stimule la natalité (8), mais ses effets sont de courte durée (1984-1987). Dès 1987 les naissances diminuent de nouveau : entre 1987 et 1992, la baisse de la natalité atteint $36 \%$, et le rétrécissement de la base de la pyramide est particulièrement prononcé (9).

En 1992, les décès l'emportent sur les naissances, pour la première fois en temps de paix, ce qui ne manque pas de susciter commentaires et polémiques : la baisse actuelle est l'écho de celle observée à la fin des années 1960 ; les femmes nées alors sont les mères d'aujourd'hui. De plus les mesures de politique familiale du début des années 1980 ont incité les couples à avoir un enfant plus tôt qu'ils ne l'auraient sans doute eu sans ces mesures. L'alternance de classes creuses et de classes pleines en Russie est pour longtemps une spécificité de l'Histoire russe: dans aucun autre pays européen cette fatalité démographique ne s'observe aussi clairement. A la fin des années 1980 , l'arrivée à l'âge adulte de générations nombreuses n'est pas étrangère aux changements politiques en cours 


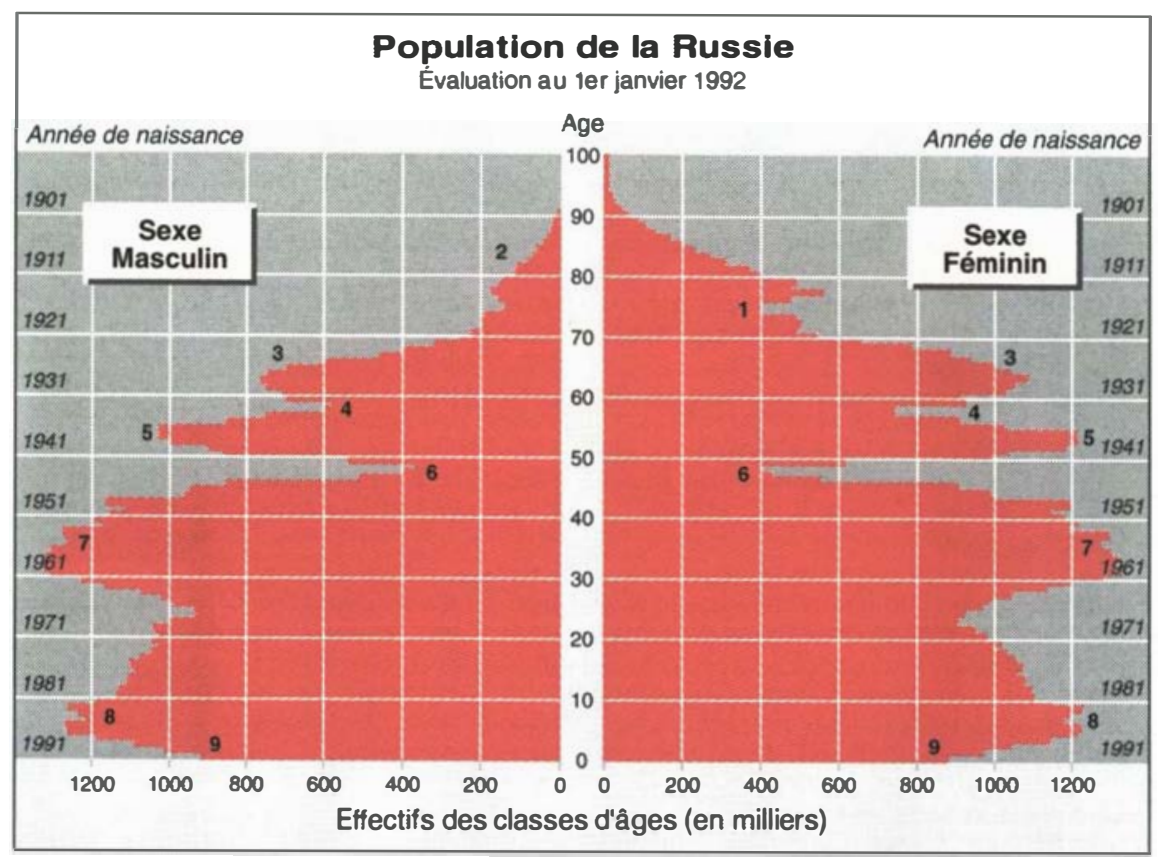

Population de la Russie
Evaluation au ler janvier 1999

Figure 1. Pyramide des âges en Russie au 1 or janvier 1992. (1) Déficit des naissances des femmes dû à la Première Guerre Mondiale. (2) Déficit des naissances des hommes dû à la Première Guerre Mondiale, plus pertes pendant la Seconde Guerre Mondiale. (3) Reprise de la natalité après 1918. (4) Baisse de la natalité : collectivisation de l'agriculture et famine. (5) Reprise de la natalité : interdiction de l'avortement. (6) Effondrement de la natalité dû à la Seconde Guerre Mondiale. (7) Baby-boom. (8) Politique nataliste, âge de fécondité des enfants du babyboom. (9) Déficit des naissances dû en partie aux classes creuses. (Source INED). 